\title{
FORUM
}

\section{Direction Indication Lights}

\author{
H. V. Anguish \\ (Cunard Steam-ship Company)
}

A ReCent Admiralty Notice to Mariners (No. 1555/1968) advises that a vessel trading the southern North Sea and the English Channel has been fitted with experimental direction indication lights in order to indicate to an approaching vessel the direction in which she is altering course and the duration of the alteration. The positioning of these lights are $10.5 \mathrm{ft}$. higher than the after masthead light and $4 \mathrm{ft}$. outboard on each side of the centre line, and they are coloured red to port and green to starboard. When altering course the appropriate light flashes until the vessel is steadied up on her new course.

Unfortunately, the lights are designed to be visible for a distance of up to $\mathrm{I} \frac{1}{2}$ miles and in my opinion until that distance off is reached the direction indicator lights will merge with the after masthead light and therefore it will not be possible to distinguish with certainty what the vessel is doing.

For the majority of cases $\mathrm{I} \frac{1}{2}$ miles is too late to start altering course if a closequarter situation is to be avoided, especially nowadays when there are more and more ships capable of 20 knots and over. To obey the collision regulations a vessel should sound the appropriate whistle signal when altering course but I think that most navigating officers will agree that whistle signals cannot be heard at much more than about half a mile. In practice, if the whistle is sounded it is taken to mean that the vessel is in a close-quarter situation and brings the captain to the bridge 'at the rush', and it is sometimes better, as a recent contributor suggested, to let sleeping captains lie! A more practical solution to the direction indication problem would be to use the Aldis lamp. This can be flashed the appropriate number of times (I for starboard, 2 for port) and can be acknowledged by the other vessel flashing an agreed signal (possibly the International Code signal $\mathrm{C}$ affirmative).

\section{Visual Signals for Manœuvre at Sea}

\author{
Captain F. Sohnke
}

HaviNG followed national and international shipping periodicals of the past years, one can readily observe that a signalling device installed on a vessel giving early and permanent signalling of the ship's course and manœuvre is urgently needed. In this report I will attempt to give brief information on previously known ideas, analyse them, draw conclusions and make a new proposal. 